\title{
Relationship Between CYP2C19 Loss-of-Function Polymorphism and Platelet Reactivities With Clopidogrel Treatment in Japanese Patients Undergoing Coronary Stent Implantation
}

Tomoyuki Nakata, MD; Masatoshi Miyahara, MD; Kaname Nakatani, MD; Hideo Wada, MD; Takashi Tanigawa, MD; Fumihiko Komada, MD; Kozo Hoshino, MD; Toshikazu Aoki, MD; Yuki Nishimura, PhD; Satoshi Tamaru, MD; Masaaki Ito, MD; Masakatsu Nishikawa, MD for the McLORDD group

Background: CYP2C19 loss-of-function genotype ( ${ }^{*} 2$ and/or ${ }^{*} 3$ alleles) is related to low responsiveness to clopidogrel, which is a risk factor for ischemic cardiac events. The contribution of these genotypes to platelet reactivity in Japanese patients in a steady state receiving dual antiplatelet therapy after coronary stenting was evaluated.

\begin{abstract}
Methods and Results: A total of 155 Japanese patients were classified according to their CYP2C19 loss-of-function genotype. Platelet reactivity was assayed by plasma levels of soluble P-selectin and platelet-derived microparticles, light transmittance aggregometry induced by ADP (ADP-LTA), shear stress-induced platelet aggregometry, vasodilator-stimulated phosphoprotein phosphorylation (VASP) index and the VerifyNow-P2Y12 assay. Linear and logistic regression models were used to assess the associations between CYP2C19 loss-of-function genotype and high on-treatment platelet reactivity. In total, 62 patients $(40.0 \%)$ were extensive metabolizers (EMs), 70 (45.2\%) were intermediate metabolizers (IMs) and $23(14.8 \%)$ were poor metabolizers (PMs). ADP-specific assays (ADP-LTA, the VASP index and VerifyNow-P2Y12) differed according to CYP2C19 genotype, with a significant gene-dose effect (PMs $>$ IMs $>$ EMs). CYP2C19 loss-of-function carrier status was associated with more frequent high platelet reactivity. CYP2C19 loss-of-function genotype alone could explain $12.2 \%, 14.3 \%$, and $14.7 \%$ of the variability in the ADPLTA, VASP and VerifyNow-P2Y12 assays, respectively.
\end{abstract}

Conclusions: CYP2C19 loss-of-function genotype is associated with more frequent high platelet reactivity, as assessed by ADP-specific platelet function tests, in Japanese patients. (Circ $J$ 2013; 77: 1436-1444)

Key Words: Clopidogrel; CYP2C19; Platelet reactivity; Stent; Thrombosis

D ual antiplatelet therapy (DAP) using aspirin and clopidogrel is the most common management strategy for patients who have undergone percutaneous coronary intervention (PCI) with stent implantation. ${ }^{1}$ Several studies have suggested that being a low-responder to clopidogrel is associated with a poor clinical outcome after acute coronary syndrome (ACS), particularly after PCI. ${ }^{2-7}$ To monitor the antiplatelet effects, several laboratory tests are available, including platelet activation markers (such as plasma levels of soluble $\mathrm{P}^{\mathrm{P}}$ selectin $^{8}$ and platelet-derived microparticles (PMPs) ${ }^{9}$ ), plate- let vasodilator-stimulated phosphoprotein (VASP) phosphorylation status, ${ }^{2}$ and platelet aggregation tests, such as light transmittance aggregometry (LTA), ${ }^{3,4,6}$ shear stress-induced platelet aggregometry (SIPA) ${ }^{10}$ and the VerifyNow assay., ${ }^{3,6}$ Differences in assays, agonist concentrations, and cut-off values have contributed to the variability in the reported prevalence of a low response to clopidogrel. ${ }^{5-7}$ Elevated platelet aggregation, indicating a low, impaired response to clopidogrel, has been associated with recurrent ischemic events. ${ }^{5-7,11}$ The whole blood VerifyNow-P2Y12 test is a rapid test that uses ADP to stimu-

Received August 28, 2012; revised manuscript received January 20, 2013; accepted January 24, 2013; released online March 8, 2013 Time for primary review: 16 days

Department of Cardiology (T.N., M.M., M.I.), Molecular and Laboratory Medicine (K.N., H.W.), Mie University Faculty of Medicine, Tsu; Department of Cardiology, Matsusaka Chuo General Hospital, Matsusaka (T.T.); Department of Internal Medicine, Matsusaka Municipal Hospital, Matsusaka (F.K.); Department of Cardiology, Nagai Hospital, Tsu (K.H.); Department of Internal Medicine, Tohyama Hospital, Tsu (T.A.); Clinical Research Support Center, Mie University Hospital, Tsu (Y.N., S.T., M.N.), Japan

Mailing address: Masakatsu Nishikawa, MD, Clinical Research Support Center, Mie University Hospital, 2-174 Edobashi, Tsu 514-8507, Japan._E-mail: nisikawa@ clin.medic.mie-u.ac.jp

ISSN-1346-9843 doi:10.1253/circj.CJ-12-1095

All rights are reserved to the Japanese Circulation Society. For permissions, please e-mail: cj@j-circ.or.jp 
late platelets in the presence of prostaglandin $\mathrm{E}_{1}$, thus making the assay more sensitive to the activity of P2Y12. ${ }^{4}$

The mechanisms leading to a low response to clopidogrel are not fully understood and are probably multifactorial. ${ }^{12,13}$ Clopidogrel is an inactive prodrug that requires several biotransformation steps to become an active inhibitor of the platelet ADP-P2Y12 receptor. After intestinal absorption, clopidogrel is metabolized in the liver by cytochrome P-450 (CYP) isozymes, including CYP2C19, 3A4/5, 1A2, $2 \mathrm{~B} 6$ and 2C9. ${ }^{14-16}$ A loss-of-function polymorphism in $C Y P 2 C 19$, known as the $C Y P 2 C 19 * 2$ and $C Y P 2 C 19 * 3$ allelic variants, has been associated with a higher level of ADP-induced platelet aggregation values in clopidogrel-treated patients, and is consequently a higher risk of major adverse cardiovascular events, including stent thrombosis. ${ }^{14-19}$ These $C Y P 2 C 19$ loss-of-function genotypes are more frequent in Asian (13-23\%) than in Caucasian (1-6\%) populations. ${ }^{20-23}$ Therefore, this genomic polymorphism may be clinically more important in Japanese patients.

In many studies, laboratory assessment of clopidogrel responsiveness has been performed using only one platelet reactivity test during the acute phase before coronary stenting. The response to clopidogrel is highly dynamic during the acute phase of myocardial infarction (MI) after clopidogrel loading, just before PCI, and most patients improve their on-treatment platelet reactivity significantly during the chronic period (1 month) after PCI and clopidogrel administration. ${ }^{24}$ The thrombotic condition of the coronary artery after resolving ischemia and platelet activation by stent implantation could be stabilized, and the isolated low responsiveness to the drug would be obtained in the chronic phase. We evaluated the relationship between $C Y P 2 C 19$ loss-of-function genotype and various platelet reactivity tests in Japanese patients in the chronic phase receiving DAP after coronary stenting. To elucidate the most appropriate method of quantifying the level of residual platelet reactivity, we examined several methods simultaneously, which included measurement of platelet activation markers (soluble P-selectin and PMPs) and platelet VASP phosphorylation status, and platelet aggregation tests (ADP-LTA, SIPA and VerifyNow-P2Y12 assays). The relative contribution of each CYP2C19 loss-of-function genotype to the interindividual variability in on-treatment platelet reactivity was also determined.

\section{Methods}

\section{Patient Population and Study Design}

This was a prospective observational study performed at multiple hospitals from December 2008 to April 2011. The Ethics Committee of Mie University Hospital approved the study protocol (No. 986) in accordance with the Declaration of Helsinki, and all patients gave their written informed consent for participation.

Patients were eligible for enrolment if they had stable coronary artery disease requiring PCI and had no known allergy to aspirin or clopidogrel in the Mie Study of Clopidogrel Low Responders in Atherothrombotic Disease Patients With/Without Diabetes (McLORDD) (Figure 1). We excluded patients with ACS (unstable angina/MI). All patients received oral loading doses of $100 \mathrm{mg}$ aspirin and $300 \mathrm{mg}$ clopidogrel 6-12 h before stent implantation. Most of the patients received a drugeluting stent. At stenting, all patients underwent intravascular ultrasound to check adequate deployment of the stent within the coronary artery. Patients were instructed to take a combination of $100 \mathrm{mg} /$ day of aspirin and $75 \mathrm{mg} /$ day of clopidogrel (maintenance dose) for 1 year. Patients who were confirmed

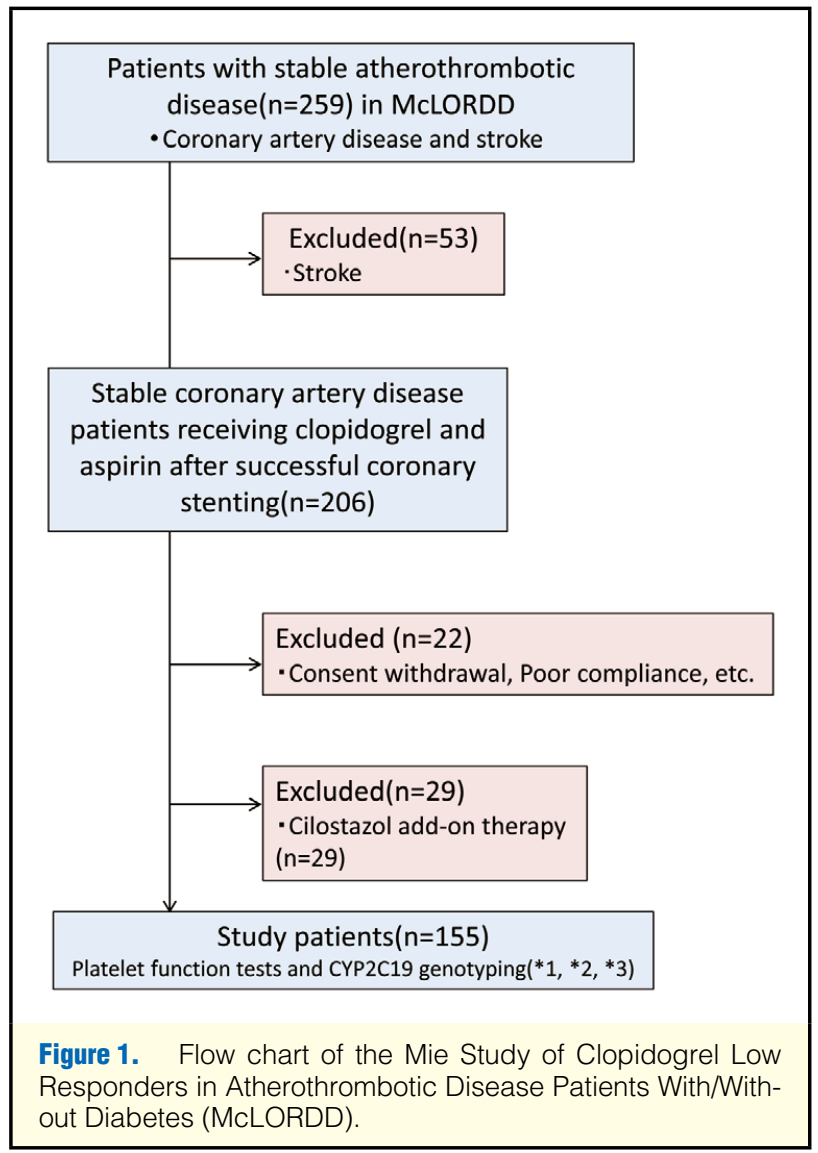

with active bleeding disease, cerebral infarction with embolization from the heart, taking anticoagulation agents, such as warfarin, and antiplatelet agents other than aspirin and clopidogrel before the surgical operation were excluded. Patients who were not eligible (as determined by the responding physician) were also excluded. For the VerifyNow-P2Y12 assay, the patients' inclusion criteria were as follows: hematocrit, $33-52 \%$; platelet count, $119,000-502,000 / \mathrm{mm}^{3}$; total cholesterol level, 98-316 mg/dl; triglycerides level, 41-824 mg/dl; and fibrinogen, $171-599 \mathrm{mg} / \mathrm{dl}$. We defined diabetes mellitus as $>6.5 \%$ of $\mathrm{HbA}_{1 \mathrm{c}}$ or treatment with insulin or hypoglycemic medication. Patients with estimated glomerular filtration rate (eGFR) $<60 \mathrm{ml} \cdot \mathrm{min}^{-1} \cdot 1.73 \mathrm{~m}^{-2}$ for 3 months were defined as having chronic kidney disease. Blood sampling for the assessment of clopidogrel response was performed once from 14 to 28 days after coronary stenting.

\section{Platelet Function Assays}

Blood samples for platelet function analysis were drawn by atraumatic venipuncture of the antecubital vein using a 21gauge needle. The initial blood sample drawn was measured for blood chemistry to measure any platelet activation induced by needle puncture. Blood was then collected into a Venoject ${ }^{\circledR}$ (Terumo, Tokyo, Japan) containing 3.8\% trisodium citrate, Vacuette $^{\circledR}$ (Greiner bio-one International, Kremsmünster, Austria) containing 3.2\% sodium citrate, and Neotube ${ }^{\circledR}$ (Nipro, Osaka, Japan) containing ACD-A and EDTA 2Na. Platelet function tests were completed within $2 \mathrm{~h}$ of blood sampling. To avoid inter-hospital variability, 2 operators performed each platelet function test in the Mie University Hospital, within $2 \mathrm{~h}$ of blood sampling; the operators were blinded to the clinical 


\begin{tabular}{|c|c|c|c|c|c|}
\hline & \multirow{2}{*}{ Total $(n=155)$} & \multicolumn{4}{|c|}{ CYP2C19 loss-of-function genotype } \\
\hline & & $\mathrm{EM}(n=62)$ & IM $(n=70)$ & PM $(n=23)$ & $P$ value \\
\hline Age, years & $69.4 \pm 10.2$ & $69.4 \pm 10.4$ & $68.8 \pm 10.5$ & $71.4 \pm 9.3$ & 0.615 \\
\hline Sex, F/M & $45 / 110$ & $13 / 49$ & $27 / 43$ & $5 / 18$ & 0.060 \\
\hline BMI $\left(\mathbf{k g} / \mathbf{m}^{2}\right)$ & $24.0 \pm 3.7$ & $24.3 \pm 3.7$ & $24.0 \pm 4.0$ & $23.1 \pm 2.8$ & 0.486 \\
\hline \multicolumn{6}{|l|}{ Previous history, n (\%) } \\
\hline Myocardial infarction & $39(25.2)$ & $11(17.7)$ & $22(31.4)$ & $6(26.1)$ & 0.194 \\
\hline Cerebral infarction & $4(2.6)$ & $1(1.6)$ & $2(2.9)$ & $1(4.3)$ & 0.803 \\
\hline \multicolumn{6}{|l|}{ Risk factors, $\mathbf{n}(\%)$} \\
\hline Current smoker & $14(9.0)$ & $7(11.3)$ & $4(5.7)$ & $3(13.0)$ & 0.406 \\
\hline Diabetes mellitus & $69(44.5)$ & $32(51.6)$ & $27(38.6)$ & $10(43.5)$ & 0.320 \\
\hline Dyslipidemia & $110(71.0)$ & $47(75.8)$ & $48(68.6)$ & $15(65.2)$ & 0.530 \\
\hline Hypertension & $96(61.9)$ & $38(61.3)$ & $42(60.0)$ & $16(69.6)$ & 0.708 \\
\hline Obesity (BMI >25) & $48(31.0)$ & $23(37.1)$ & $21(30.0)$ & $4(17.4)$ & 0.212 \\
\hline Chronic kidney disease & $6(3.9)$ & 2 (3.2) & $3(4.3)$ & $1(4.3)$ & 1.000 \\
\hline \multicolumn{6}{|l|}{ No. of risk factors, $n(\%)$} \\
\hline 1 & $36(23.2)$ & $11(17.7)$ & $21(30.0)$ & $4(17.4)$ & 0.193 \\
\hline 2 & $39(25.2)$ & $15(24.2)$ & $15(21.4)$ & $9(39.1)$ & 0.231 \\
\hline$>3$ & 67 (43.2) & $32(51.6)$ & $26(37.1)$ & $9(39.1)$ & 0.224 \\
\hline \multicolumn{6}{|l|}{ Medication, n (\%) } \\
\hline Aspirin & $153(98.7)$ & $62(100)$ & $68(97.1)$ & $23(100)$ & 0.636 \\
\hline Statin & $98(63.2)$ & $43(69.4)$ & $39(55.7)$ & $16(69.6)$ & 0.212 \\
\hline Proton-pump inhibitor & $49(31.6)$ & $24(38.7)$ & $22(31.4)$ & $3(13.0)$ & 0.078 \\
\hline $\mathrm{H} 2$ receptor antagonist & $24(15.5)$ & $6(9.7)$ & $13(18.6)$ & $5(21.7)$ & 0.220 \\
\hline \multicolumn{6}{|l|}{ CYP2C19, n (\%) } \\
\hline EM & $62(40.0)$ & & & & \\
\hline IM & $70(45.2)$ & & & & \\
\hline PM & $23(14.8)$ & & & & \\
\hline
\end{tabular}

BMI, body mass index; EM, extensive metabolizer; IM, intermediate metabolizer; PM, poor metabolizer.

results and $C Y P 2 C 19$ genotyping.

For the measurement of ADP-LTA and SIPA, platelet-rich plasma was prepared by centrifugation at $120 \mathrm{~g}$ for $15 \mathrm{~min}$ at room temperature. The platelet count was adjusted to $3.0 \times 10^{5 /}$ $\mathrm{mm}^{3}$ to standardize the aggregation study, by adding homologous platelet-poor plasma obtained by centrifugation of the blood at $1,500 \mathrm{~g}$ for $10 \mathrm{~min}$. ADP $(20 \mu \mathrm{mol} / \mathrm{L})$-induced platelet aggregation (ADP-LTA) was monitored turbidimetrically at $37^{\circ} \mathrm{C}$, using an aggregometer (MCM Hema Tracer 712, MC Medical Inc, Tokyo, Japan). SIPA was monitored by a turbidimetric technique with a modified cone-plate viscometer (6-108 dyne $/ \mathrm{cm}^{2}$ over $6 \mathrm{~min}$ ) using platelet-rich plasma, as described previously. ${ }^{10}$ The ADP-LTA and SIPA responses were quantified as the maximum extent of aggregation. ${ }^{10}$

VASP phosphorylation analysis was performed within $24 \mathrm{~h}$ of blood collection by an experienced investigator using Platelet VASP kits (Diagnostica Stago, Asnières, France), according to the manufacturer's instructions. Flow cytometric analysis was performed using a FACS caliber cytometer (Becton Dickinson, Lincoln Park, NJ, USA). The platelet population was identified on its forward and side scatter distributions, and 10,000 platelet events were gated and analyzed for mean fluorescence intensity. ${ }^{2}$ The mean fluorescence intensity corresponding to each experimental condition (ADP and ADP+ prostaglandin $\mathrm{E}_{1}$ ) was determined to establish a ratio that directly correlated with the VASP phosphorylation status. The ratio, [(mean fluorescence intensityPGE1-mean fluorescence intensity $A D P+P G E 1) /$ mean fluorescence intensityPGE1] $\times 100$, was used in this study as the VASP index corresponding to the ratio of the VASP phosphorylation of activated platelets vs. resting platelets and expressed as a percentage of platelet reactivity.

VerifyNow-P2Y12 platelet reaction units (PRU) were measured by a turbidimetric method (Accumetrics Inc, San Diego, CA, USA), based on an optical detection system as an increase in light transmittance. ${ }^{4}$ The test cartridge contained a lyophilized preparation of human fibrinogen-coated beads, platelet agonist, preservative and buffer. ADP $(20 \mu \mathrm{mol} / \mathrm{L})$ was used to maximally activate the platelets by binding to the P2Y1 and P2Y12 platelet receptors, and PGE1 was used to suppress the ADP-induced P2Y1-mediated increase in intracellular calcium levels, and thereby reduce the activation contributed by P2Y1 and thus increase assay sensitivity.

Enzyme-linked immunosorbent assay kits were used to determine the plasma levels of PMPs and soluble P-selectin, using the protocols provided by the manufacturers (JIMRO PDMP ELISA kit, Otsuka Pharmaceutical Inc, Tokyo, Japan and Human sP-selectin ELISA Kit, Invitrogen Co, Carlsbad, CA, USA).

\section{CYP2C19 Genotyping}

A QIAamp Blood Kit (Qiagen, Hilden, Germany) was used to isolate genomic DNA. CYP2C19 polymorphisms were analyzed for the nonfunctional alleles $* 2$ and $* 3$ by identifying 2 polymorphic positions: $681 \mathrm{G}>\mathrm{A}$ in exon 5 and $636 \mathrm{G}>\mathrm{A}$ in exon 4 , respectively. The region including the polymorphisms was amplified by polymerase chain reaction (PCR) and genotyping was performed using the SNaPshot Multiplex Kit 

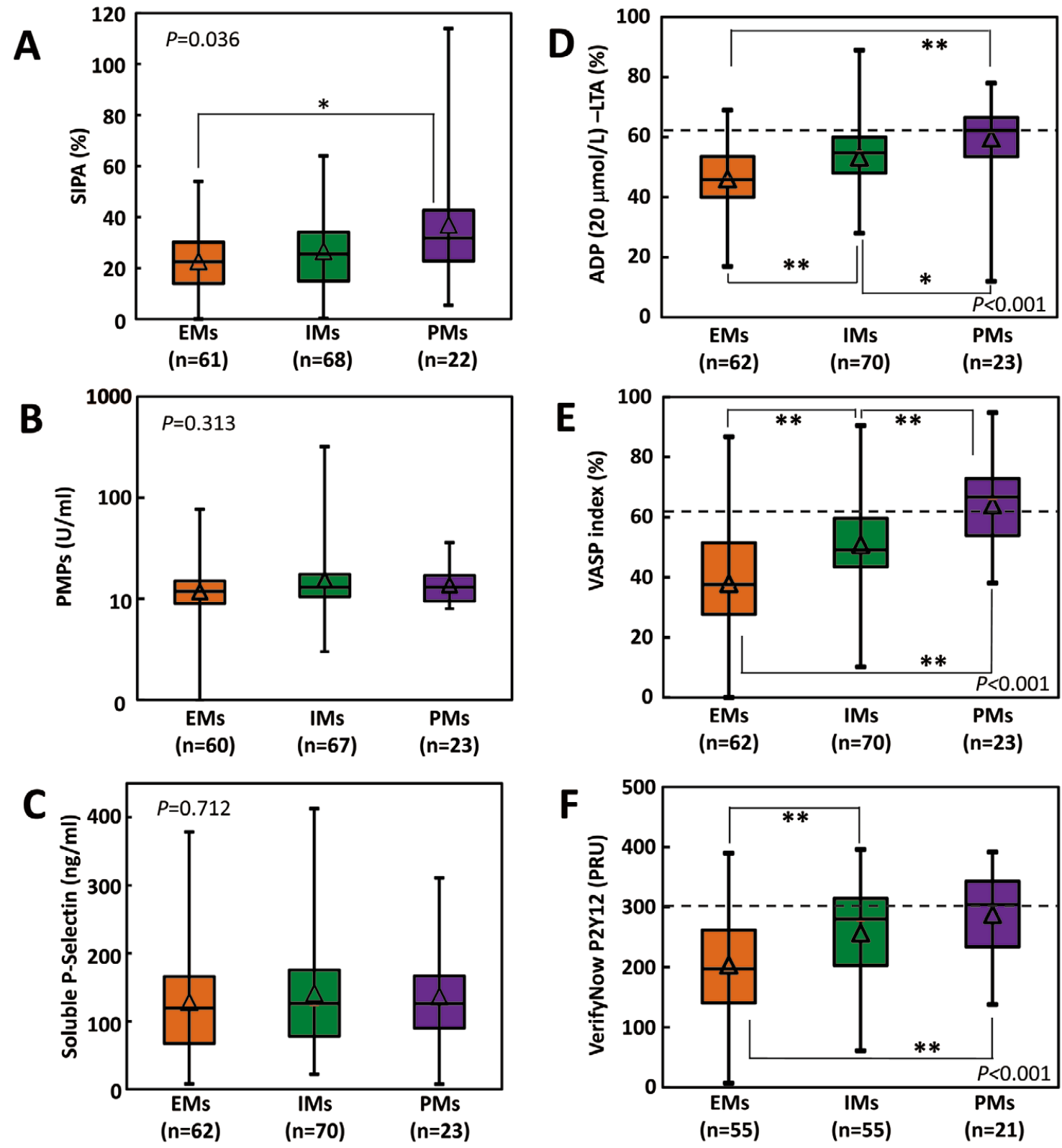

Figure 2. Effect of CYP2C19 genotype on platelet reactivity assessed by SIPA (A), PMPs (B) soluble P-selectin (C), ADP-LTA (D), the VASP index (E), and VerifyNow-P2Y12 (F). Box and whisker plots show mean value $(\triangle)$, median (horizontal lines), $25^{\text {th }}$ and $75^{\text {th }}$ percentiles (box) and $10^{\text {th }}$ and $90^{\text {th }}$ percentiles (error bars). EMs, extensive metabolizers (orange color); IMs, intermediate metabolizers (green color); PMs, poor metabolizers (purple color); LTA, light transmittance aggregometry; PMPs, platelet-derived microparticles; PRU, platelet reaction units; SIPA, shear stress-induced platelet aggregometry; VASP, platelet vasodilator-stimulated phosphoprotein. ${ }^{*} \mathrm{P}<0.05,{ }^{*} \mathrm{P}<0.001$.

(Applied Biosystems, Carlsbad, CA, USA) and the ABI Prism $^{\circledR} 310$ Genetic Analyzer. The following genotypes were determined: $C Y P 2 C 19 * 1 / * 1$ (extensive metabolizer: EM), $C Y P 2 C 19 * 1 / * 2$ (intermediate metabolizer: IM), $C Y P 2 C 19 * 1 / * 3$ (IM), $C Y P 2 C 19 * 2 / * 2$ (poor metabolizer: PM), CYP2C19*2/*3 $(\mathrm{PM})$, and $C Y P 2 C 19 * 3 / * 3(\mathrm{PM})$. PCR and subsequent melting curve analysis were performed using the Lightcycler device (Roche Applied Science, Mannheim, Germany) and software. Control samples confirmed by sequencing were included in each run.

\section{Statistical Analysis}

The sample size was calculated to detect whether the patients with CYP2C19 loss-of-function genotype had a 2-fold or larger increase in the occurrence of high platelet reactivity $(25 \%)$ as compared with $C Y P 2 C 19$ wild-type patients, according to a previous report. ${ }^{25}$ To demonstrate such a difference, the inclusion of 152 patients was required to yield $80 \%$ power with an alpha risk error of 0.05 , as the frequency of $C Y P 2 C 19 * 1$ allele is $60 \%$ in Japanese patients.

Continuous variables are presented as mean \pm standard de- 


\begin{tabular}{|c|c|c|c|c|c|c|}
\hline & \multicolumn{2}{|c|}{ ADP-LTA } & \multicolumn{2}{|c|}{ VASP } & \multicolumn{2}{|c|}{ VerifyNow-P2Y12 } \\
\hline & $\mathbf{R}^{2}$ & $P$ value & $\mathbf{R}^{2}$ & $P$ value & $\mathbf{R}^{2}$ & $P$ value \\
\hline CYP2C19 loss-of-function & $12.2 \%$ & $<0.001$ & $14.3 \%$ & $<0.001$ & $14.7 \%$ & $<0.001$ \\
\hline Clinical variables* & $9.5 \%$ & 0.004 & $14.8 \%$ & $<0.001$ & $16.7 \%$ & $<0.001$ \\
\hline CYP2C19 loss-of-function + clinical variables & $15.3 \%$ & $<0.001$ & $23.4 \%$ & $<0.001$ & $26.2 \%$ & $<0.001$ \\
\hline$P$ for change ${ }^{\dagger}$ & & $<0.001$ & & $<0.001$ & & $<0.001$ \\
\hline
\end{tabular}

Percentage of variability in platelet reactivity explained was defined as the coefficient determination $\left(R^{2}\right), 100 \%$. ${ }^{*}$ Sex, age and diabetes mellitus were significantly associated with platelet reactivity in univariate analysis $(P<0.1)$. tP value for the change in $\mathrm{R}^{2}$ when adding clinical variables to CYP2C19 loss-of-function genotype.

LTA, light transmittance aggregometry; VASP, platelet vasodilator-stimulated phosphoprotein.

viation. Categorical variables were compared using Fisher's exact test and the $\chi^{2}$ test. Agreement between the different tests was determined by kappa statistics, and $95 \%$ confidence intervals (CIs) were calculated. The relationship between different methods was evaluated with the Pearson correlation coefficient (r) and the Student's t-test; P-values were considered significant at $<0.05$. Two-tailed non-parametric tests were used to analyze differences between groups (EMs, IMs, and PMs) (Kruskal-Wallis test and Steel-Dwass test). Sensitivities and specificities of the VASP and VerifyNow-P2Y12 assays were based on the results from ADP-LTA. Positive and negative predictive values were calculated according to the Bayes theorem. Multivariate linear regression analysis with calculation of the coefficient of determination $\left(\mathrm{R}^{2}\right)$ was used to identify the independent contribution of each of the factors to the interindividual variability in platelet reactivity. Results in the $4^{\text {th }}$ quartiles (4Q) by ADP-LTA, the VerifyNow-P2Y12 assay and the VASP index were considered as high platelet reactivity (clopidogrel low-responder). Multivariate binary logistic regression analysis was used to compute adjusted odds ratio (OR) with corresponding 95\% CIs for exhibiting high platelet reactivity compared with not exhibiting high platelet reactivity, adjusting for the variables. Analyses were performed with SPSS 18.0 for Windows (SPSS Institute, Chicago, IL, USA).

\section{Results}

The clinical characteristics and polymorphisms of $C Y P 2 C 19$ in the 155 patients enrolled in this study (Figure 1) are shown in Table 1. The distribution of CYP2C19 polymorphisms $(\mathrm{n}=155)$ was as follows: 62 patients $(40.0 \%)$ were $C Y P 2 C 19$ wild-type $(* 1 / * 1)$ homozygotes; 11 patients $(7.1 \%)$ were CYP2C19*2 homozygotes (*2/*2); 43 patients $(27.7 \%)$ were CYP2C19*2 heterozygotes $(* 1 / * 2) ; 2$ patients $(1.3 \%)$ were CYP2C19*3 homozygotes $(* 3 / * 3) ; 27$ patients $(17.4 \%)$ were $C Y P 2 C 19 * 3$ heterozygotes $(* 1 / * 3)$; and 10 patients $(6.5 \%)$ had both $C Y P 2 C 19 * 3$ and $C Y P 2 C 19 * 2$ mutant alleles $(* 2 / * 3)$. The patients could be divided into 3 groups according to their $C Y P 2 C 19$ genotype: $62(40.0 \%)$ EMs $(C Y P 2 C 19 * 1 / * 1)$, $70(45.2 \%) \mathrm{IMs}(C Y P 2 C 19 * 1 / * 2$ and $C Y P 2 C 19 * 1 / * 3)$ and $23(14.8 \%)$ PMs $(C Y P 2 C 19 * 2 / * 2, \quad C Y P 2 C 19 * 2 / * 3$, and $C Y P 2 C 19 * 3 / * 3)$. These data indicate that $C Y P 2 C 19$ loss-offunction genotypes in Japanese patients are more frequent than in Caucasians. ${ }^{17-20}$ The baseline characteristics of the patients were compared among the three CYP2C19 genotype groups (Table 1). There were no significant differences in any of the parameters, although a trend was present indicating that females were more frequently IMs than males (females $60.0 \%$ vs. males $39.3 \%, \mathrm{P}=0.060$ ).

The relationships between $C Y P 2 C 19$ genotype and various platelet reactivity tests (soluble P-selectin and PMPs; platelet VASP index, SIPA, ADP $(20 \mu \mathrm{mol} / \mathrm{L})$-LTA and VerifyNowP2Y12) were analyzed (Figure 2). These laboratory tests were performed at 22.5 \pm 5.4 days after clopidogrel administration. ADP-LTA, VASP index and VerifyNow-P2Y12 all increased according to the degree of $C Y P 2 C 19$ loss-of-function genotype (PMs $>$ IMs $>$ EMs), indicating a gene-dose effect. Soluble P-selectin, PMPs and SIPA results were not related to CYP2C19 genotype, although SIPA in PMs was significantly higher than in EMs. The 24 patients with mild anemia $[\mathrm{Hb}$ $11.1 \pm 1.5 \mathrm{~g} / \mathrm{dl}, 14$ females] at blood sampling could not be assessed by VerifyNow-P2Y12, because the apparatus could only assay the aggregation in blood with $\mathrm{Hb} \geq 12.0 \mathrm{~g} / \mathrm{dl}$. In the ADP-specific platelet function tests, including ADP-LTA, the VASP index or the VerifyNow-P2Y12 assay, there was a statistically significant difference among the three genotype groups ( $\mathrm{P}<0.001$, Kruskal-Wallis test). CYP2C19 loss-of-function genotyping explained $12.2 \%, 14.3 \%$ and $14.7 \%$ of the interindividual variability in the ADP-LTA, VASP index and VerifyNowP2Y12 assay, respectively, compared with $15.3 \%, 23.4 \%$ and $26.2 \%$ when clinical factors were included (Table 2). The clinical variables independently associated with the magnitude of platelet reactivity were age, male sex and diabetes mellitus $\left(\mathrm{HbA}_{1 \mathrm{c}}>6.5 \%\right.$ or being treated as diabetic). There was no association between body mass index, chronic kidney disease or proton-pump inhibitors and the magnitude of platelet reactivity.

A significant correlation between the different platelet function tests assessing the clopidogrel response was observed: $\mathrm{r}=0.565(\mathrm{P}<0.001)$ for ADP-LTA and the VASP index $(\mathrm{n}=155)$; $\mathrm{r}=0.675(\mathrm{P}<0.001)$ for ADP-LTA and VerifyNow-P2Y12; $\mathrm{r}=0.565(\mathrm{P}<0.001)$ for the VASP index and VerifyNow-P2Y12 (Figure 3). A significant, although low, agreement between 2 tests was observed: $\kappa=0.366, \mathrm{P}<0.001$ for ADP-LTA and the VerifyNow-P2Y12 assay; $\kappa=0.190, \mathrm{P}=0.016$ for ADP-LTA and the VASP index; $\kappa=0.242, \mathrm{P}=0.003$ for the VASP index and VerifyNow-P2Y12 assay.

Results in 4Q by ADP-LTA, VASP index and VerifyNow$\mathrm{P} 2 \mathrm{Y} 12$ assay were considered as high platelet reactivity (clopidogrel low-responder) in this study. The corresponding 4Q values were a maximum aggregation $\geq 62 \%$ for ADP-LTA, VASP index $\geq 61.6 \%$, and $\geq 302$ PRU for the VerifyNow-P2Y12 assay. Based on the results from ADP-LTA, a cut-off value of $61.6 \%$ for the VASP index provided $47 \%$ sensitivity and $80 \%$ specificity, a positive predictive value of $38 \%$ and a negative predictive value of $85 \%$. The cut-off value of $302 \mathrm{PRU}$ for VerifyNow-P2Y12 provided a sensitivity of $70 \%$, specificity of $88 \%$, a positive predictive value of $64 \%$ and a negative predictive value of $91 \%$. High platelet reactivity with a 4Q value $\geq 62 \%$ by ADP-LTA was detected in 5 cases $(8.1 \%)$ among the EMs ( $n=62), 14(20.0 \%)$ among the IMs $(n=70)$, 

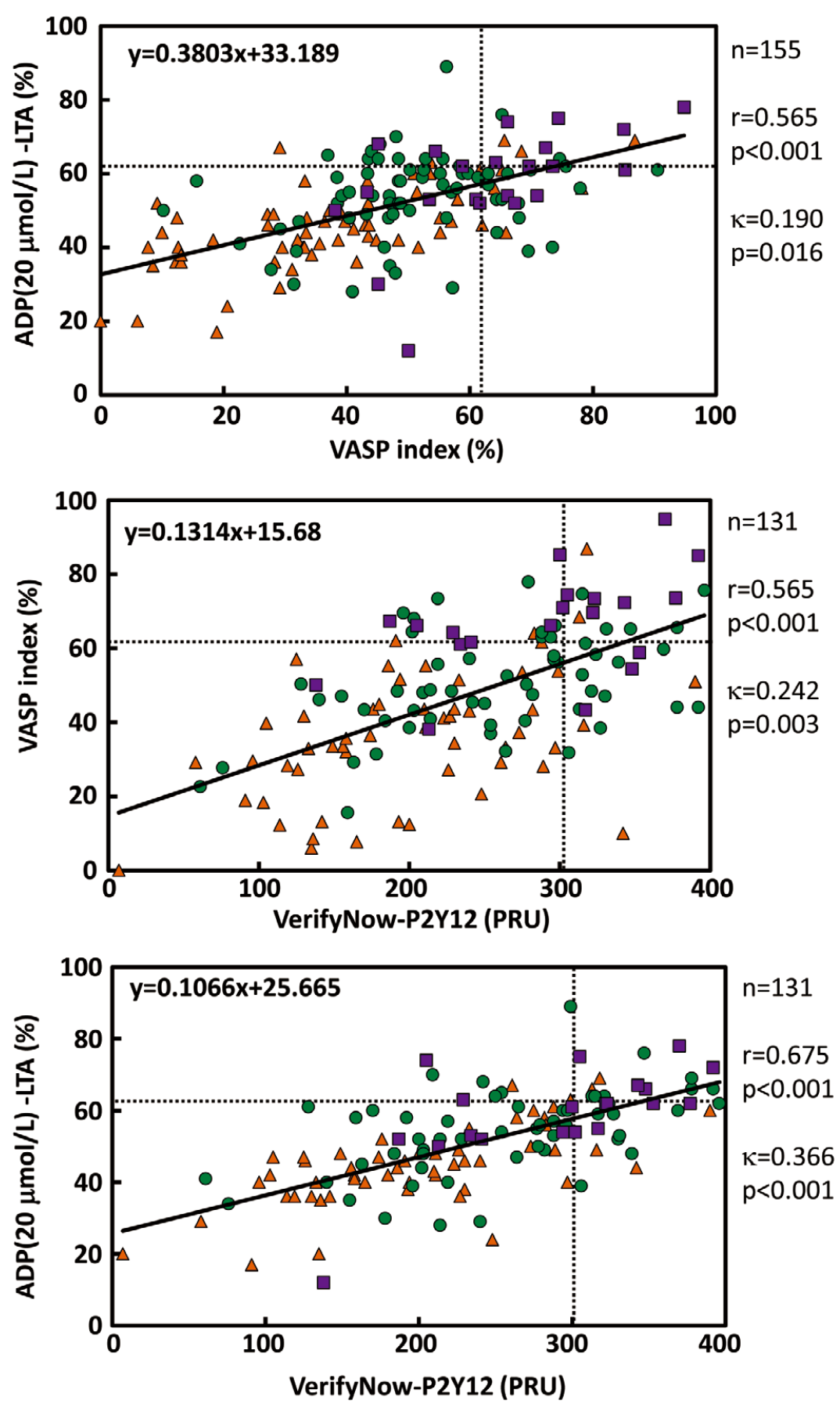

Figure 3. Correlation and agreement between different platelet parameters using ADP $(20 \mu \mathrm{mol} / \mathrm{L})-\mathrm{LTA}$, the VASP index, and VerifyNow-P2Y12 assay. Open symbols represent individual measurements (EM: $\triangle$; IM: O; PM: $\square$ ). Cut-off values are indicated by dotted lines ( $\geq 62 \%$ for ADP ( $20 \mu \mathrm{mol} / \mathrm{L})$-LTA, $\geq 302$ PRU for VerifyNow-P2Y12, and $\geq 61.6 \%$ for the VASP index). EM, extensive metabolizers; IM, intermediate metabolizers; PM, poor metabolizers; LTA, light transmittance aggregometry; PRU, platelet reaction unit; VASP, platelet vasodilator-stimulated phosphoprotein.

and $13(56.5 \%)$ among the PMs $(n=23)$. High platelet reactivity with a $4 \mathrm{Q}$ value $\geq 61.6 \%$ by the VASP index was detected in 8 cases (12.9\%) among the EMs ( $\mathrm{n}=62), 18(25.7 \%)$ among the IMs $(n=70)$, and $13(56.5 \%)$ among the PMs $(n=23)$. High platelet reactivity with a $4 Q$ value $\geq 302$ PRU by the VerifyNowP2Y12 assay was detected in 4 cases $(7.3 \%)$ among the EMs $(\mathrm{n}=55), 18(32.7 \%)$ among the IMs $(\mathrm{n}=55)$, and $11(52.4 \%)$ among the PMs $(n=21)$. In each ADP-specific platelet function test, the order of frequency of high platelet reactivity by DAP therapy was PMs $>$ IMs $>$ EMs.

To determine predictors of high platelet reactivity, multi- variate logistic analysis was performed, including CYP2C19 loss-of function genotype, in addition to clinical variables (male gender, age, eGFR, and diabetes mellitus) that were associated with the platelet reactivity in multivariate linear regression. CYP2C19-PMs and CYP2C19-IMs were compared with CYP2C19 EMs. Only PMs predicted the high platelet reactivity in each ADP-specific assay, but a trend was observed regarding IMs (Figure 4). PMs had an approximately 9 to 15 times increase in the occurrence of high platelet reactivity as compared with EMs; this association appeared to be stronger for patients with IMs. 


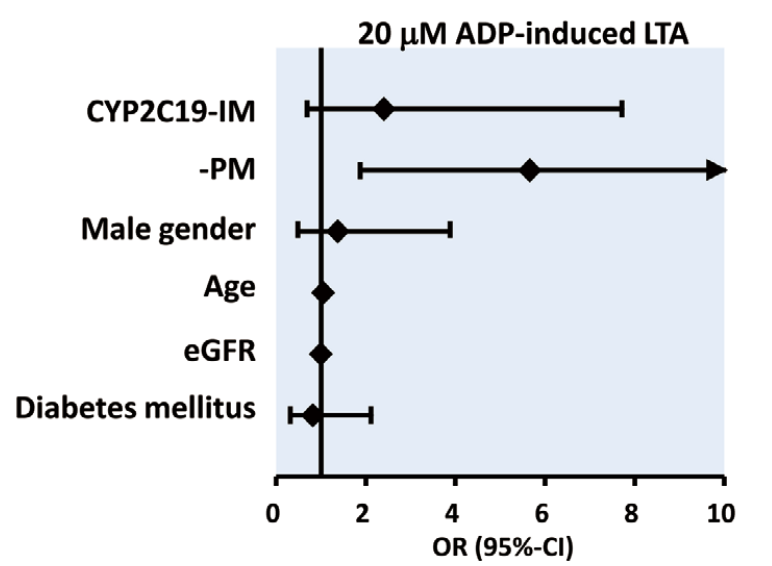
OR $95 \%-\mathrm{Cl} \quad$-value
2.40 (0.75 to 7.72) 0.141
5.66 (1.88 to 17.11) 0.002
1.38 (0.49 to 3.88$) \quad 0.542$
1.05 (1.00 to 1.11) 0.075
$1.00 \quad$ (0.97 to 1.02$) \quad 0.772$
0.82 (0.32 to 2.13 ) 0.683

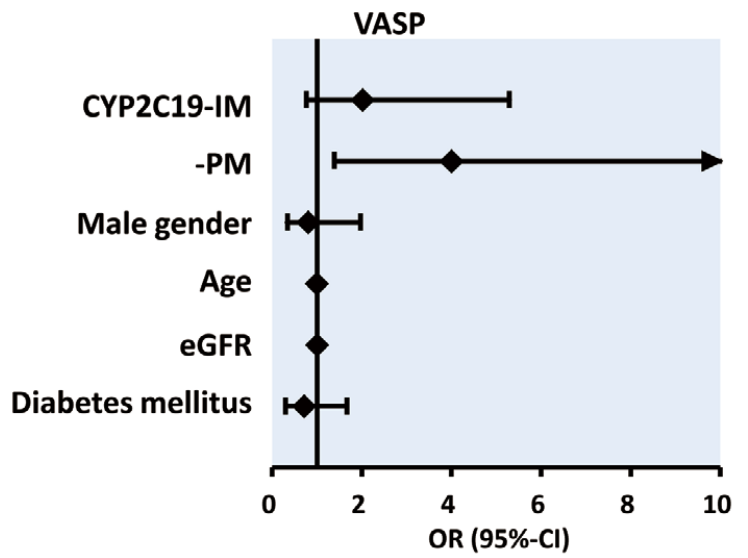
OR
95\%-Cl p-value
$2.02 \quad(0.77$ to 5.30$) \quad 0.153$
$4.01 \quad$ (1.41 to 11.42) 0.009
$0.81 \quad$ (0.33 to 1.97) 0.643
$1.00 \quad$ (0.96 to 1.04) 0.958
$1.00 \quad$ (0.98 to 1.02) 0.725
$0.72 \quad(0.31$ to 1.66$) \quad 0.438$

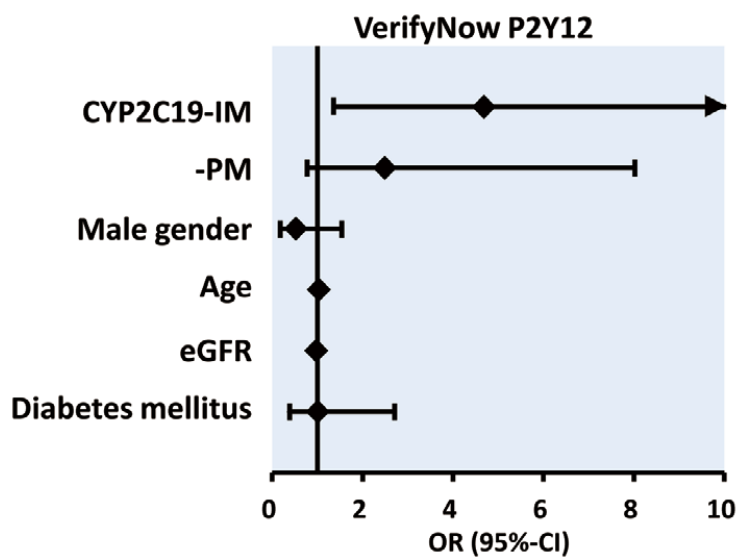

OR $95 \%-\mathrm{Cl} \quad \mathrm{p}$-value

4.68 (1.36 to 16.09) 0.014

$2.50 \quad$ (0.78 to 7.97) 0.123

$0.53 \quad$ (0.18 to 1.54) 0.240

1.04 (0.98 to 1.10) 0.210

$0.98 \quad$ (0.95 to 1.00) 0.074

$1.01 \quad(0.38$ to 2.67$) \quad 0.986$

Figure 4. Predictors of high platelet reactivity. Adjusted odds ratio with corresponding 95\% confidence interval [OR (95\% CI)] for exhibiting high platelet reactivity vs. not exhibiting high platelet reactivity, as determined with $20 \mu \mathrm{mol} / L$ ADP-LTA, VASP index and VerifyNow-P2Y12 assays. The results were analyzed using multivariate binary logistic model containing CYP2C19 loss-offunction genotypes (PM, IM, and EM) in addition to clinical variables that were associated with the platelet reactivity in multivariate linear regression $(P<0.05)$. CYP2C19-PMs and -IMs were compared with CYP2C19-EMs. EM, extensive metabolizer; IMs, intermediate metabolizer; PMs, poor metabolizer; LTA, light transmittance aggregometry; PRU, platelet reaction unit; VASP, platelet vasodilator-stimulated phosphoprotein.

\section{Discussion}

In the present study group, the laboratory response to clopidogrel in the stable phase after clopidogrel administration and stent implantation was assessed to evaluate the relationship between clopidogrel response and CYP2C19 loss-of-function genotype. Among various tests examined in this study, ADPLTA, platelet VASP and VerifyNow-P2Y12 were strongly affected by $C Y P 2 C 19$ loss-of-function genotype. Bouman et al reported that ADP $(20 \mu \mathrm{mol} / \mathrm{l})-\mathrm{LTA}$, the VASP index and VerifyNow-P2Y12 assay correlate with the in vitro plasma levels of the active metabolite of clopidogrel, ${ }^{26}$ which is im- 
portant when estimating the relative contribution of $C Y P 2 C 19$ loss-of-function genotype to the generation of the active metabolite. These 3 platelet function tests have been shown to be capable of predicting clinical outcome in PCI patients administered clopidogrel. ${ }^{6,27,28}$ In the present study, the results of the VerifyNow-P2Y12 assay and VASP assay significantly correlated with those of ADP-LTA, which is considered the gold standard method. A stronger correlation with ADP-LTA was observed with the VerifyNow-P2Y12 assay. The rapidity and ease of use of this method suggest that it might be valuable for point-of-care testing of patients receiving P2Y12 receptor blockers.

We divided post-treatment residual platelet reactivity into quartiles of each platelet function test, and patients in $4 \mathrm{Q}$ were defined as clopidogrel low-responders (ie, high platelet reactivity). Our study showed that 4Q values for identifying clopidogrel low-responders among Japanese PCI patients were $\geq 62 \%$ for ADP-LTA, $\geq 302$ PRU for VerifyNow-P2Y12 and $\geq 61.6 \%$ for the VASP index. Using these values, the VerifyNow-P2Y12 assay revealed a higher sensitivity and specificity for detecting high residual platelet reactivity, based on the results from ADP-LTA, which is similar to recent studies. ${ }^{29,30}$ In recent clinical trials, $, 3,6$ receiver-operating characteristic curves were used to determine the optimal cut-off values for platelet function tests to predict major cardiovascular events after PCI. The POPULAR study ${ }^{6}$ suggested that ADP-LTA, VerifyNowP2Y12 and Plateletworks are able to identify patients at higher risk for ischemic cardiac events after PCI. Findings from the present prospective study showed that the optimal cut-off values for ADP $(20 \mu \mathrm{mol} / \mathrm{L})-\mathrm{LTA}$ and VerifyNow-P2Y12 were $64.5 \%$ and 236 PRU, respectively. There have been several other trials outside of Japan that have associated high residual platelet reactivity with clinical outcome, and the cut-off values based on receiver-operating characteristic analyses were as follows: ADP ( $5 \mu \mathrm{mol} / \mathrm{L})-\mathrm{LTA},>46 \%$; VerifyNow-P2Y12, $>235$ PRU; VASP index, $>50 \% .^{2-4,6,7,27,28}$ The $4 \mathrm{Q}$ value of $\geq 62 \%$ for ADP-LTA obtained from our study is similar to the cut-off value in previous studies, whereas those of $\geq 61.6 \%$ for the VASP index and $\geq 302$ PRU for VerifyNow-P2Y12 were both higher than the cut-off values reported by other investigators outside Japan. Using a VASP index $>50 \%$, high residual platelet reactivity would be seen in $45.2 \%$ (70/155), comprising $74.3 \%$ (52/70) CYP2C19 loss-of-function genotype patients (IM: 34 cases, PM: 18 cases). Using a VeryfyNow-P2Y12 assay $>235$ PRU, a high residual platelet reactivity would be seen in $50.4 \%$ (66/131), which contained 74.2\% (49/66) CYP2C19 loss-of-function genotype patients (IM: 35 cases, PM: 14 cases). The reason for the discrepancy in cut-off points between our data and previous Caucasian studies remains unknown, but may be partly explained by the high frequency of the CYP2C19 lossof-function variants $* 2$ and $* 3$ in the Japanese population.

CYP2C19 polymorphisms are not associated with platelet aggregation at baseline, ${ }^{16}$ which suggests that $C Y P 2 C 19$ is the major genetic mediator of the laboratory clopidogrel response. Our study results suggest that the relative contribution of CYP2C19 loss-of-function genotype to the variable response in Japanese patients is 2- to 3-fold higher than in Caucasian patients. ${ }^{25}$ We found that residual platelet reactivity during clopidogrel treatment was strongly affected by CYP2C19 lossof-function genotype; the order of the magnitude of the residual platelet reactivity was $\mathrm{PM}>\mathrm{IM}>\mathrm{EM}$ with $\mathrm{ADP}-\mathrm{LTA}$, VerifyNow-P2Y12 or the VASP index, indicating a gene-dose effect. The present study shows that in addition to CYP2C19 loss-of-function genotype, clinical variables such as sex, age and diabetes contribute significantly to the degree of platelet reactivity. $C Y P 2 C 19$ loss-of-function alleles were identified as the only significant predictor of high residual platelet activity in each ADP-specific assay. However, clinical variables such as sex, age and diabetes mellitus were not related to the risk of the high platelet reactivity in our study. This might be attributed to the small sample size and the inclusion of the stable patients. The frequency of $C Y P 2 C 19$ loss-of-function alleles is much higher among Asian populations, including Japanese; therefore, a low response to clopidogrel might be potentially more important in those populations. However, the j-Cypher registry ${ }^{31}$ shows that the rate of stent thrombosis in Japanese patients is lower than in Caucasian patients. Taken together with the results from the $\mathrm{j}$-Cypher registry, our present study suggests that the cut-off values for platelet function tests of a low response to clopidogrel could differ according to ethnicity and/or country. Other factors, both genetic and nongenetic, that affect the clopidogrel response may also vary between ethnic groups. Global studies in ethnically diverse populations are warranted.

\section{Study Limitations}

This was an observational prospective study, and the small study population meant that we could not clarify the relationship between residual platelet reactivity and patients' outcomes. This study did not determine plasma levels of the active metabolite of clopidogrel, so we could not provide direct evidence of reduced antiplatelet activity by clopidogrel among patients carrying $C Y P 2 C 19$ loss-of function genotypes. In addition, we did not survey all types of $C Y P 2 C 19$ polymorphisms. A nationwide study enrolling many more high-risk patients should be performed to clarify the relationships among CYP2C19 loss-of-function genotypes, residual platelet reactivity and clinical outcome.

\section{Conclusions}

CYP2C19 loss-of-function genotype with the *2 and/or *3 allele is associated with higher residual platelet reactivity, as assessed by ADP-specific platelet function tests, including ADP-LTA, VASP and VerifyNow-P2Y12. The contribution of $C Y P 2 C 19$ loss-of-function genotype to interindividual variability in clopidogrel platelet reactivity in Japanese patients seems to be higher than that of clinical variables.

\section{Acknowledgments}

The McLORDD study was an academic research project supported by a research grant from Daiichi Sankyo Company Limited, Tokyo, Japan. The study sponsor was not involved in the study design, or the collection, analysis or interpretation of the data.

\section{Disclosures}

Dr Nishikawa M has received honoraria for lectures from Daiichi Sankyo Inc, Sanofi-Aventis, and Otsuka Pharmaceutical Inc. The other authors declare no conflict of interest concerning this study.

\section{References}

1. Cross J. Antiplatelet therapy for improving post-PCI outcomes: Interpreting current treatment guidelines for optimal management of the post-ACS patient. Am J Manag Care 2009; 15(Suppl): S48-S53.

2. Frere C, Cuisset T, Quilici J, Camoin L, Carvajal J, Morange PE, et al. ADP-induced platelet aggregation and platelet reactivity index VASP are good predictive markers for clinical outcomes in non-ST elevation acute coronary syndrome. Thromb Haemost 2007; 98: 838-843.

3. Sibbing D, Braun S, Morath T, Mehilli J, Vogt W, Schömig A, et al. Platelet reactivity after clopidogrel treatment assessed with point-ofcare analysis and early drug-eluting stent thrombosis. J Am Coll Cardiol 2009; 53: 849-856. 
4. Price MJ, Endemann S, Gollapudi RR, Valencia R, Stinis CT, Levisay $\mathrm{JP}$, et al. Prognostic significance of post-clopidogrel platelet reactivity assessed by a point-of-care assay on thrombotic events after drugeluting stent implantation. Eur Heart J 2008; 29: 992-1000.

5. Angiolillo DJ, Suryadevara S, Capranzano P, Zenni MZ, Guzman LA, Bass TA. Antiplatelet drug response variability and the role of platelet function testing: A practical guide for interventional cardiologists. Catheter Cardiovasc Interv 2009; 73: 1-14.

6. Breet NJ, van Werkum JW, Bouman HJ, Kelder JC, Ruven HJT, Bal ET, et al. Comparison of platelet function tests in predicting clinical outcome in patients undergoing coronary stent implantation. JAMA 2010; 303: 754-762.

7. Sobieraj-Teague M, Eikelboom JW. Point-of-care testing for assessment of adequacy of oral antiplatelet therapy in patients with cardiovascular disease. Future Cardiol 2010; 6: 289-299.

8. Nagy B Jr, Szuk T, Debreceni IB, Kappelmayer J. Platelet derived microparticle levels are significantly elevated in patients treated by elective stenting compared to subjects with diagnostic catheterization alone. Platelets 2011; 21: 147-151.

9. Patlig G, Chello M, Pasceri V, Colonna D, Colonna G, Pepe LL, et al. Pretreatment with different loading dose of clopidogrel influences $\mathrm{P}$-selectin levels in patients undergoing percutaneous coronary intervention: Results from the ARMYDA-2 SELECT substudy. Cardiovasc Med 2011; 12: 151 - 156.

10. Tanigawa T, Nishikawa M, Kitai T, Ueda Y, Okinaka T, Makino K, et al. Increased platelet aggregability in response to shear stress in acute myocardial infarction and its inhibition by combined therapy with aspirin and cilostazol after coronary intervention. Am J Cardiol 2000; 85: 1054-1059.

11. Motoda C, Ueda H, Hayashi Y, Toyofuku M, Okimoto T, Otsuka M, et al. Impact of platelet reactivity to adenosine diphosphate before implantation of drug-eluting stent on subsequent adverse cardiac events in patients with stable angina. Circ J 2012; 76: 641-649.

12. Momary KM, Dorsch MP. Factors associated with clopidogrel nonresponsiveness. Future Cardiol 2010; 6: 195-210.

13. Geisler T, Schaeffeler E, Dippon J, Winter S, Buse V, Bischofs C, et al. CYP2C19 and nongenetic factors predict poor responsiveness to clopidogrel loading dose after coronary stent implantation. Pharmacogenomics 2008; 9: 1251-1259.

14. Mega JL, Close SL, Wiviott SD, Shen L, Hockett RD, Brandt JT, et al. Cytochrome P-450 polymorphisms and response to clopidogrel. $N$ Engl J Med 2009; 360: 354-362.

15. Simon T, Verstuyft C, Mary-Krause M, Quteineh L, Drouet E, Méneveau N, et al. Genetic determinants of response to clopidogrel and cardiovascular events. N Engl J Med 2009; 360: 363-375.

16. Shuldiner AR, O'Connell JR, Bliden KP, Gandhi A, Ryan K, Horenstein RB, et al. Association of cytochrome P450 2C19 genotype with the antiplatelet effect and clinical efficacy of clopidogrel therapy. JAMA 2009; 302: 849-857.

17. Hulot JS, Collet JP, Silvain J, Pena A, Bellemain-Appaix A, Barthélémy $\mathrm{O}$, et al. Cardiovascular risk in clopidogrel-treated patients according to cytochrome $\mathrm{P} 4502 \mathrm{C} 19 * 2$ loss-of-function allele or proton pump inhibitor coadministration: A systematic meta-analysis. J Am Coll Cardiol 2010; 56: 134-143.

18. Sawada T, Shinke T, Shite J, Honjo T, Haraguchi Y, Nishio R, et al. Impact of cytochrome $\mathrm{P} 4502 \mathrm{C} 19 * 2$ polymorphism on intra-stent thrombus after drug-eluting stent implantation in Japanese patients receiving clopidogrel. Circ J 2011; 75: 99-105.

19. Nishio R, Shinke T, Otake H, Sawada T, Haraguchi Y, Shinohara M, et al. Effect of cytochrome P450 2C19 polyporphism on target lesion outcome after drug-eluting stent implantation in Japanese patients receiving clopidogrel. Circ J 2012; 76: 2348-2355.

20. Lee JM, Park S, Shin DJ, Choi D, Shim CY, Ko YG, et al. Relation of genetic polymorphisms in the cytochrome P450 gene with clopi- dogrel resistance after drug-eluting stent implantation in Koreans. Am J Cardiol 2009; 104: 46-51.

21. Goldstein JA, Ishizaki T, Chiba K, de Morais SM, Bell D, Krahn PM, et al. Frequencies of the defective CYP2C19 alleles responsible for the mephenytoin poor metabolizer phenotype in various Oriental, Caucasian, Saudi Arabian and American black populations. Pharmacogenetics 1997; 7: 59-64.

22. Jinnai T, Horiuchi H, Makiyama T, Tazaki J, Tada T, Akao M, et al. Impact of CYP2C19 polymorphism on the antiplatelet effect of clopidogrel in an actual clinical setting in Japan. Circ J 2009; 73: $1498-$ 1503 .

23. Yamamoto K, Hokimoto S, Chitose T, Morita K, Ono T, Kaikita K, et al. Impact of CYP2C19 polymorphism on residual platelet reactivity in patients with coronary heart disease during antiplatelet therapy. J Cardiol 2011; 57: 194-201.

24. Campo G, Parrinello G, Ferraresi P, Lunghi B, Tebaldi M, Miccoli M, et al. Prospective evaluation of on-clopidogrel platelet reactivity over time in patients treated with percutaneous coronary intervention relationship with gene polymorphisms and clinical outcome. J Am Coll Cardiol 2011; 57: 2474-2483.

25. Bouman HJ, Harmsze AM, van Werkum JW, Breet NJ, Bergmeijer $\mathrm{TO}$, ten Cate $\mathrm{H}$, et al. Variability in on-treatment platelet reactivity explained by CYP2C19*2 genotype is modest in clopidogrel pretreated patients undergoing coronary stenting. Heart 2011; 97: 1239 1244.

26. Bouman HJ, Parlak E, van Werkum JW, Breet NJ, ten Cate H, Hackeng CM, et al. Which platelet function test is suitable to monitor clopidogrel responsiveness? A pharmacokinetic analysis on the active metabolite of clopidogrel. J Thromb Haemost 2010; 8: $482-$ 488.

27. Sofi F, Marcucci R, Gori AM, Giusti B, Abbate R, Gensini GF. Clopidogrel non-responsiveness and risk of cardiovascular morbidity: An updated meta-analysis. Thromb Haemost 2010; 103: $841-$ 848.

28. Bonello L, Camoin-Jau L, Arques S, Boyer C, Panagides D, Wittenberg $\mathrm{O}$, et al. Adjusted clopidogrel loading doses according to vasodilatorstimulated phosphoprotein phosphorylation index decrease rate of major adverse cardiovascular events in patients with clopidogrel resistance: A multicenter randomized prospective study. J Am Coll Cardiol 2008; 51: 1404-1411.

29. Paniccia R, Antonucci E, Gori AM, Marcucci R, Giglioli C, Antoniucci $\mathrm{D}$, et al. Different methodologies for evaluating the effect of clopidogrel on platelet function in high-risk coronary artery disease patients. J Thromb Haemost 2007; 5: 1839-1847.

30. Gremmel T, Steiner S, Seidinger D, Koppensteiner R, Panzer S, Kopp CW. Comparison of methods to evaluate clopidogrel-mediated platelet inhibition after percutaneous intervention with stent implantation. Thromb Haemost 2009; 101: 333-339.

31. Kimura T, Morimoto T, Nakagawa Y, Tamura T, Kadota K, Yasumoto $\mathrm{H}$, et al; j-Cypher Registry Investigators. Antiplatelet therapy and stent thrombosis after sirolimus-eluting stent implantation. Circulation 2009; 119: 987-995.

\section{Appendix}

The complete list of McLORDD Investigators is as follows: Tomoyuki Nakata, MD; Masaaki Ito, MD; Masatoshi Miyahara, MD; Toshiki Sawai, MD; Akihiro Tuji, MD; Muneyoshi Tanimura, MD; Satoshi Ota, MD; Takashi Tanigawa, MD; Tairo Kurita, MD; Toshikazu Aoki, MD; Kozo Hoshino, MD; Takafumi Hashimoto, MD; Shiro Nakamori, MD; Fumihiko Komada, MD; Hitoshi Kakimoto, MD; Mashio Nakamura, MD; Hideo Wada, MD; Kaname Nakatani, MD; Yuki Nishimura, PhD; Tomomi Yamada, PhD; Satoshi Tamaru, MD; Masakatsu Nishikawa, MD, PhD. 